University of Nebraska - Lincoln

DigitalCommons@University of Nebraska - Lincoln

\title{
Very High Risk of Therapeutic Failure with Chloroquine for Uncomplicated Plasmodium falciparum and $P$. vivax Malaria in Indonesian Papua
}

Iwa W. Sumawinata

U.S. Naval Medical Research Unit \# 2

Bernadeta

Provincial Health Service

Budhi Leksana

U.S. Naval Medical Research Unit \# 2

Awalludin Sutamihardja

U.S. Naval Medical Research Unit \# 2

Purnomo

U.S. Naval Medical Research Unit \# 2

See next page for additional authors

Follow this and additional works at: https://digitalcommons.unl.edu/usnavyresearch

Sumawinata, Iwa W.; Bernadeta; Leksana, Budhi; Sutamihardja, Awalludin; Purnomo; Subianto, Budi; Sekartuti; Fryauff, David J.; and Baird, J. Kevin, "Very High Risk of Therapeutic Failure with Chloroquine for Uncomplicated Plasmodium falciparum and P. vivax Malaria in Indonesian Papua" (2003). U.S. Navy Research. 58.

https://digitalcommons.unl.edu/usnavyresearch/58

This Article is brought to you for free and open access by the U.S. Department of Defense at DigitalCommons@University of Nebraska - Lincoln. It has been accepted for inclusion in U.S. Navy Research by an authorized administrator of DigitalCommons@University of Nebraska - Lincoln. 


\section{Authors}

Iwa W. Sumawinata, Bernadeta, Budhi Leksana, Awalludin Sutamihardja, Purnomo, Budi Subianto, Sekartuti, David J. Fryauff, and J. Kevin Baird 


\title{
VERY HIGH RISK OF THERAPEUTIC FAILURE WITH CHLOROQUINE FOR UNCOMPLICATED PLASMODIUM FALCIPARUM AND P. VIVAX MALARIA IN INDONESIAN PAPUA
}

\author{
IWA W. SUMAWINATA, BERNADETA, BUDHI LEKSANA, AWALLUDIN SUTAMIHARDJA, PURNOMO, \\ BUDI SUBIANTO, SEKARTUTI, DAVID J. FRYAUFF, AND J. KEVIN BAIRD \\ United States Naval Medical Research Unit No. 2, Jakarta, Indonesia; Provincial Health Service, Abepura, Papua, Indonesia; \\ Infectious Disease Research Center, Ministry of Health, Jakarta, Indonesia
}

\begin{abstract}
Chloroquine remains the first-line therapy for uncomplicated malaria in Indonesia. Among a series of trials of chloroquine for malaria on this archipelago conducted since 1990, we now report the highest risk of therapeutic failure yet observed. A clinical trial of standard chloroquine therapy for uncomplicated malaria at Arso PIR V in northeastern Indonesian Papua was conducted during 1995. We enrolled 104 non-immune subjects infected with Plasmodium falciparum $(\mathrm{n}=55), P$. vivax $(\mathrm{n}=29)$, or $P$. falciparum plus $P$. vivax $(\mathrm{n}=20)$ and administered supervised standard chloroquine therapy $(10+10+5 \mathrm{mg} / \mathrm{kg}$ at 24 -hour intervals $)$. The 28 -day cumulative incidence of therapeutic failure was $95 \%$ for P. falciparum, $84 \%$ for P. vivax, and $100 \%$ for mixed infections. Only one subject each for P. falciparum and $P$. vivax remained free of parasites at day 28 . All recurrent parasitemias occurred with whole blood levels of chloroquine plus desethylchloroquine exceeding $100 \mathrm{ng} / \mathrm{ml}$. These findings document almost complete failure of chloroquine against $P$. falciparum or P. vivax near the northeastern coast of Indonesian Papua.
\end{abstract}

\section{INTRODUCTION}

Chloroquine still constitutes first-line therapy against uncomplicated malaria caused by Plasmodium falciparum and $P$. vivax in many endemic areas. Combined therapeutic strategies under consideration by developing nations include chloroquine plus other standard antimalarials such as sulfadoxine/ pyrimethamine. ${ }^{1}$ Combining chloroquine with agents such as chlorpheniramine, which apparently reverse the process responsible for resistance, constitute another approach. ${ }^{2}$ Whether used as monotherapy or in combination with other agents, chloroquine remains a mainstay for therapy of malaria in the developing world. Thus, therapeutic assessment of chloroquine constitutes a key element of strategic thinking in the development of treatment policies. . $^{3,4}$

We have conducted assessments of chloroquine for treatment of uncomplicated $P$. falciparum and $P$. vivax in northeastern Papua (formerly known as Irian Jaya), Indonesia. ${ }^{5-8}$ Three of these reports described resistance to chloroquine in $P$. vivax. Another study ${ }^{9}$ found relatively low risk of therapeutic failure with chloroquine therapy of $P$. vivax $(22 \%$ at day 14). Subsequent studies of $P$. vivax in the same region found higher risk of therapeutic failure (31-53\% at day 14$)^{7,8}$ Similar studies in the region evaluated chloroquine combined with primaquine ${ }^{7}$ or doxycycline ${ }^{10}$ against $P$. vivax. Risk of therapeutic failure with chloroquine for $P$. falciparum at day 14 post-therapy ranged from $57 \%$ to $84 \%$ in this region. ${ }^{6,8,10}$

The continued use of chloroquine for uncomplicated $P$. falciparum and $P$. vivax malaria in Indonesian Papua points to the lack of practical therapeutic options in the setting of a frontier area of a developing nation. Indonesian authorities have not adopted policies that would permit distribution of drugs such as mefloquine, either alone or as combined therapy, largely as a consequence of prohibitive cost. Effective therapies may be purchased in bulk for as little as US \$1 per adult treatment (e.g., mefloquine plus artesunate as marketed in Cambodia), but chloroquine or pyrimethamine/ sulfadoxine treatments cost approximately US \$0.20 (as marketed in Indonesia). Moreover, the longer and more complex dosing regimens of the new therapeutic agents carry the hidden and substantial cost of adapting the acquisition and dis- tribution mechanism, along with educating healthcare providers and patients. In the case of Indonesia, the fourth most populous nation in the world, such commitments engage many thousands of government officers and many millions of citizens. In addition to compelling evidence of the inadequacy of current antimalarials, changes to policy and practice will require fiscal resources not currently available to the health infrastructure.

This report contributes to the case for adopting alternative therapies for uncomplicated $P$. falciparum and $P$. vivax malaria in Indonesian Papua by describing the highest risk of therapeutic failure yet documented in the region. We know of no other region in Indonesia with risk of therapeutic failure even approaching that reported here from northeastern Papua. Substantiation of this may allow singling out the region for the distribution and use of relatively expensive and effective combined therapies. Thus limiting the scale of application would substantially diminish the hidden costs of adopting new therapeutic strategies.

\section{MATERIALS AND METHODS}

Study sites. The study was conducted during October and November 1995 in Arso PIR V, in northeastern Papua, Indonesia. This transmigration village is located within $7 \mathrm{~km}$ of the border with Papua New Guinea and approximately $50 \mathrm{~km}$ south of the Pacific Ocean coast. The residents of Arso PIR V were predominantly transmigrants from Java, consisting mostly of young families. Most residents had moved into the village by January 1995. Malaria in the region was hyperendemic to holoendemic and transmitted by mosquitoes of the Anopheles punctulatus group. ${ }^{11}$ These mosquitoes feed predominantly in villages between dusk and dawn. All residents shared approximately equal risk of exposure to biting anophelines. Figure 1 shows the age-specific prevalence of malaria at enrollment. Prevalence of parasitemia among the 349 of the approximately 1,100 residents sampled was $79 \%$, with a $P$. falciparum to $P$. vivax ratio of approximately $3: 1$. Prevalence across age groups was not significantly different $(P>0.2)$, and this corroborates cross-sectional studies elsewhere in the region, ${ }^{12}$ suggesting onset of acquired immunity 


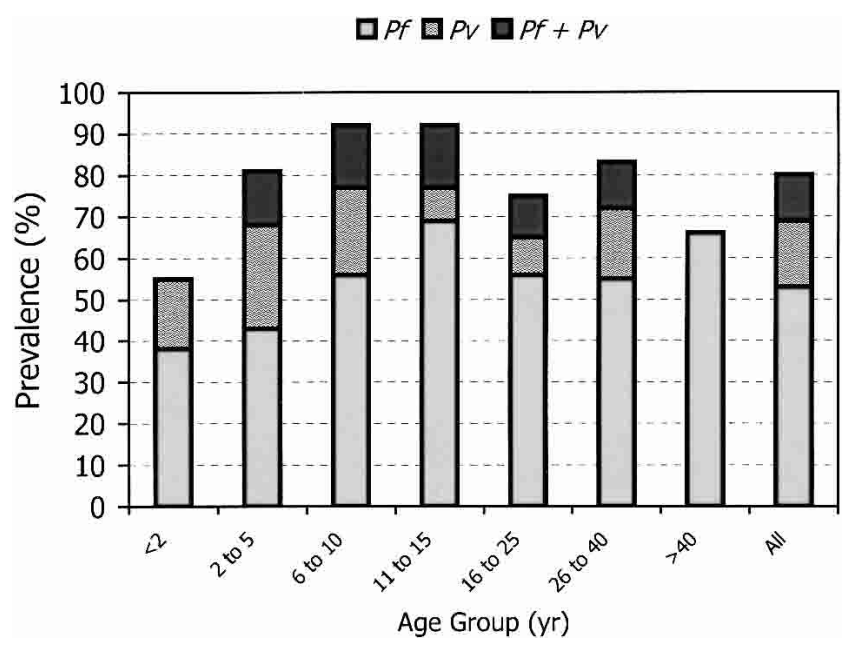

FIGURE 1. Age-specific prevalence of malaria at enrollment in the study. $P f=$ Plasmodium falciparum; $P v=P$. vivax; $\mathrm{yr}=$ years.

in adults only after 12-24 months of exposure to infection. We considered these findings objective evidence of a broad lack of clinical immunity in the study population.

Study subjects. Study subjects were recruited from among those found slide-positive during the cross-sectional screening. Subjects ranged in age from 5 to 40 years $($ median $=24)$. Asexual parasitemia counts at enrollment ranged from 40 to $16,480 / \mu \mathrm{L}$ for $P$. falciparum (geometric mean $=766 / \mu \mathrm{L}$ ) and $40-13,520 / \mu \mathrm{L}$ for $P$. vivax (geometric mean $=824 / \mu \mathrm{L})$. We excluded subjects meeting the criteria of the World Health Organization for severe or complicated malaria, pregnant or lactating women, and children less than five years of age. Eligible subjects provided informed consent in accordance with U.S. Navy regulations governing the use of human subjects of medical research (SECNAVINST 3900.39B). A protocol detailing this work was reviewed and approved by American and Indonesian institutional review boards.

Therapy and follow-up. Subjects received directly observed therapy with chloroquine phosphate (uncoated scored tablets containing $150 \mathrm{mg}$ base, Resochin ${ }^{\mathrm{TM}}$; P.T. Bayer Indonesia, Jakarta, Indonesia) in daily doses of $10 \mathrm{mg} / \mathrm{kg}$ on day 0 and day 1 , and a $5 \mathrm{mg} / \mathrm{kg}$ dose on day 2 . Subjects were observed for 30 minutes and repeated doses vomited in that time. Primaquine therapy for subjects infected by $P$. vivax was withheld until day 28 or at time of rescue therapy (oral quinine sulfate tablets; $10 \mathrm{mg} / \mathrm{kg}$ three times a day for seven days) with recurrent parasitemia. Thick and thin blood films were collected on days $0,1,2,3,4,7,11,14,18,21$, and 28 , or at any time a subject complained of illness. Blood films were collected at the home or place of work/school. Subjects were queried about their recovery and well being during home visits.

Microscopy. Thick and thin blood films were stained with standard Giemsa reagents and examined under $1,000 \times$, oil immersion light microscopy by experienced and certified research technicians. At least 200 fields were examined before a slide was considered negative. Positive blood films were recorded by the count of asexual parasites per 200 white blood cells. This value was converted to parasites per microliter of blood by assuming a white blood cell count of $8,000 / \mu \mathrm{L}$.
Whole blood chloroquine levels. Peripheral blood collected into $100-\mu l$ heparinized capillary tubes was expelled onto filter paper (No. 1; Whatman, Maidstone, United Kingdom) discs on days 0 (before therapy), 3 , and 28 , or the day of rescue therapy of recurrent parasitemia. These blots were air-dried for several hours and placed into individual sealable plastic envelopes. These were stored at ambient temperature and protected from exposure to light or moisture for several months prior to analysis. We extracted and measured by highperformance liquid chromatography levels of chloroquine and its primary metabolite, desethylchloroquine (DCQ), using methods detailed elsewhere. ${ }^{8,13}$

Classification of the therapeutic response. We considered recurrent parasitemia with $P$. falciparum during the 28 -day evaluation consistent with a resistant classification, provided there was evidence of good absorption of therapy (day 3 level of chloroquine plus DCQ $>500 \mathrm{ng} / \mathrm{ml}$ ). For $P$. vivax, we considered recurrent parasitemia during the 28-day evaluation resistant to chloroquine if it occurred with $\geq 100 \mathrm{ng} / \mathrm{ml}$ of chloroquine plus DCQ (the minimal effective concentration), along with evidence of good absorption of therapy (> 500 $\mathrm{ng} / \mathrm{ml}$ of chloroquine plus DCQ on day 3 ). The rationale for $P$. vivax classification has been explained elsewhere. ${ }^{14}$ In this non-immune population, we considered parasitemia objective evidence of risk of clinical disease, whether disease was present or not at the point of observation.

Risk of therapeutic failure. We used life tables to estimate interval-specific and cumulative incidence (risk) of therapeutic failure. Cumulative incidence (CI) was calculated as follows: $\mathrm{CI}_{\mathrm{x}}=1-\left[\left(1-\mathrm{CI}_{\mathrm{x}-1}\right)\left(1-\mathrm{IR}_{\mathrm{x}}\right)\right]$, where $\mathrm{IR}$ is the interval risk, $\mathrm{X}$ is the interval, and $\mathrm{X}-1$ is the prior interval. Recurrences consistent with a resistance classification were considered incident cases in the life table calculation.

Interpretation of the life table estimates of risk was according to species and interval of risk. For both $P$. falciparum and $P$. vivax, the 14-day cumulative risk of therapeutic failure was viewed as a conservative estimate of the prevalence of resistance to chloroquine in the community. These relatively early recurrences were considered more likely to be recrudescence than those appearing relatively late (days 15-28) when reinfection or relapse was more likely to confound the estimate of risk. The 28-day cumulative risk of recurrence was viewed as an estimate of therapeutic failure due to resistance, reinfection, or relapse.

\section{RESULTS}

Chloroquine plus DCQ blood levels. Table 1 lists the chloroquine plus DCQ whole blood levels prior to therapy on day 0 , on day 3 , or the day of recurrent parasitemia for P. falciparum or $P$. vivax. The mean level of chloroquine plus DCQ prior to administration of supervised therapy was 198, 200, and $234 \mathrm{ng} / \mathrm{ml}$ for $P$. falciparum, $P$. vivax, and mixed infections, respectively. The proportion of subjects with evidence of chloroquine on day 0 was $92 \%$ for $P$. falciparum, $83 \%$ for $P$. vivax, and $90 \%$ for mixed infections. The chloroquine plus DCQ levels at day 3 confirmed uniformly good absorption, with all subjects having $>500 \mathrm{ng} / \mathrm{ml}$. The chloroquine plus DCQ levels on the day of persistent or recurrent parasitemia prompting alternative therapy were at least $142 \mathrm{ng} / \mathrm{ml}$ and as high as 4,423 ng/ml. The proportion of subjects with persistent or recurrent parasitemia with chloroquine plus DCQ levels 
TABLE 1

Mean (range) whole blood levels of chloroquine plus desethylchloroquine during evaluation

\begin{tabular}{|c|c|c|c|c|c|c|c|}
\hline \multirow[b]{2}{*}{ Infection } & \multicolumn{2}{|c|}{ Day 0} & \multicolumn{2}{|r|}{ Day 3} & \multicolumn{3}{|c|}{ Day of recurrence } \\
\hline & $\mathrm{n}$ & $\mathrm{ng} / \mathrm{ml}$ (range) & $\mathrm{n}$ & $\mathrm{ng} / \mathrm{ml}$ (range) & $\mathrm{n}$ & ng/ml (range) & $\%>\mathrm{MEC}^{*}$ \\
\hline P. falciparum & 51 & $198(0-922)$ & 51 & $2,069(866-8,870)$ & 49 & $714(142-3,583)$ & 98 \\
\hline$P$. vivax & 29 & $200(0-843)$ & 29 & $1,704(914-3,489)$ & 25 & $889(180-2,754)$ & 100 \\
\hline P. falciparum plus $P$. vivax & 20 & $234(0-795)$ & 20 & $1,588(997-2,368)$ & 18 & $953(238-4,423)$ & 100 \\
\hline
\end{tabular}

$* \mathrm{MEC}=$ minimal effective concentration: $200 \mathrm{ng} / \mathrm{ml}$ for Plasmodium falciparum and $100 \mathrm{ng} / \mathrm{ml}$ for $P$. vivax.

exceeding the minimal effective concentration $(200 \mathrm{ng} / \mathrm{ml}$ for $P$. falciparum and $100 \mathrm{ng} / \mathrm{ml}$ for $P$. vivax) was $98 \%$ for $P$. falciparum, $100 \%$ for $P$. vivax, and $100 \%$ for mixed infections.

Risk of therapeutic failure. Table $2 \mathrm{~A}$ lists the life table calculation for estimating risk of therapeutic failure of chloroquine against $P$. falciparum. The evaluation began on day 0 with 55 subjects at risk. Almost half the subjects failed to clear parasitemia by day 4 and thus prompted rescue therapy with quinine. By day 14 of the evaluation, only 14 subjects remained at risk, and by day 28 , only one subject remained free of parasitemia. One subject was lost to follow-up and three others required alternative therapy as a consequence of intercurrent parasitemia by $P$. vivax. The 14-day risk of therapeutic failure was $84 \%$. At day 28 , the risk was $95 \%$.

Table 2B lists the life table calculation for estimating risk of therapeutic failure of chloroquine against $P$. vivax. The evaluation began on day 0 with 29 subjects at risk. Seven subjects failed to clear parasitemia by day 4 and thus prompted rescue therapy with quinine. Three subjects had intercurrent $P$. falciparum parasitemia and received rescue therapy with quinine by day 4 . By day 14 , only nine subjects remained at risk, and by day 28 , only one subject remained free of parasitemia. All losses to follow-up listed in the withdrawals column were due to intercurrent $P$. falciparum prompting rescue therapy. Evaluation of therapeutic failure for $P$. falciparum and $P$. vivax mixed infections began on day 0 with 20 subjects at risk. Thirteen of these failed to clear parasitemia by day 4 (10 P.

TABLE 2

Life table estimates of risk of therapeutic failure of chloroquine

\begin{tabular}{cccccc}
\hline \multicolumn{5}{c}{ A Plasmodium falciparum } \\
\hline $\begin{array}{c}\text { Interval } \\
\text { (day) }\end{array}$ & $\begin{array}{c}\text { Sample } \\
\text { at risk }\end{array}$ & $\begin{array}{c}\text { Incident } \\
\text { cases }\end{array}$ & Withdrawals & $\begin{array}{c}\text { Interval } \\
\text { risk }\end{array}$ & $\begin{array}{c}\text { Cumulative } \\
\text { risk }\end{array}$ \\
\hline 0 & 55 & 0 & 0 & 0 & 0 \\
4 & 54 & 25 & 0 & 0.4630 & 0.4630 \\
7 & 29 & 5 & 0 & 0.1724 & 0.5556 \\
11 & 24 & 10 & 0 & 0.4167 & 0.7408 \\
14 & 14 & 5 & 1 & 0.3707 & 0.8368 \\
18 & 8 & 5 & 1 & 0.6667 & 0.9456 \\
21 & 2 & 0 & 1 & 0 & 0.9456 \\
28 & 1 & 0 & 1 & 0 & 0.9456 \\
\hline \multicolumn{7}{c}{} & 0 & B Plasmodium vivax & & \\
\hline Interval & Sample & Incident & & Interval & Cumulative \\
(day) & at risk & cases & Withdrawals & risk & risk \\
\hline 0 & 29 & 0 & 0 & 0 & 0 \\
4 & 29 & 7 & 0 & 0.2545 & 0.2545 \\
7 & 29 & 5 & 3 & 0.1714 & 0.3827 \\
11 & 19 & 3 & 3 & 0.2400 & 0.5309 \\
14 & 9 & 1 & 0 & 0.1111 & 0.5830 \\
18 & 8 & 4 & 3 & 0.6154 & 0.8396 \\
21 & 1 & 0 & 0 & 0 & 0.8396 \\
28 & 1 & 0 & 0 & 0 & 0.8396 \\
\hline
\end{tabular}

falciparum and 3 P. vivax). By day 14 , all of the remaining seven subjects had recurrent parasitemia (6 $P$. falciparum and 1 P. vivax).

Table 3 lists the proportion of infections in this study population having parasitologic evidence and chloroquine plus DCQ levels supporting the diagnosis of resistance to chloroquine. The total number of infections by $P$. falciparum or $P$. vivax (placing the mixed infections in both columns) was 75 and 49. All withdrawals except one were due to the administration of alternative therapy for parasitemia by the other species: 7 for $P$. falciparum and 25 for $P$. vivax. Plasmodium falciparum interfered with the $P$. vivax evaluation in approximately half of the infections. Among the $67 P$. falciparum infections (all had adequate absorption), all but one required alternative therapy, and all but another one occurred with chloroquine plus DCQ levels above the minimal effective concentration. Therefore, $99 \%$ of the $P$. falciparum infections successfully evaluated ended with therapeutic failure. Among the 24 infections by $P$. vivax that were evaluated (all had adequate absorption), 23 ended with a requirement for alternative therapy. Therefore, $96 \%$ of infections by $P$. vivax fully evaluated ended with a requirement for alternative therapy.

In almost all instances of early therapeutic failure, the subjects had substantially lower parasite counts and had recovered clinically. Later recurrences also had substantially lower parasite counts relative to enrollment and most remained asymptomatic. No enrolled subject progressed to severe or complicated disease, and none required hospitalization during the evaluation.

\section{DISCUSSION}

These findings demonstrate very high risk of therapeutic failure with standard chloroquine therapy for uncomplicated $P$. falciparum and $P$. vivax malaria in northeastern Indonesian Papua. The proportion of subjects successfully completing the in vivo test and presenting evidence of resistance was $99 \%$ and $96 \%$ for $P$. falciparum and $P$. vivax, respectively (Table

TABLE 3

Confirmed resistance to chloroquine at Arso PIR V, Papua

\begin{tabular}{lcc}
\hline & $\begin{array}{c}\text { Plasmodium } \\
\text { falciparum }\end{array}$ & $\begin{array}{c}\text { Plasmodium } \\
\text { vivax }\end{array}$ \\
\hline Sample at risk & 75 & 49 \\
Withdrawals & 8 & 25 \\
Adequate absorption* & 67 & 24 \\
Recurrence with $>$ MEC $\dagger$ & 66 & 23 \\
Resistant to chloroquine & 66 & 23 \\
$\%$ resistant to chloroquine & 99 & 96 \\
\hline * Adequate absorption was $>500 \mathrm{ng} / \mathrm{ml}$ of chloroquine plus desethylchloroquine on day 3. \\
† MEC $=$ minimal effective concentration: $200 \mathrm{ng} / \mathrm{ml}$ for $P$. falciparum and $100 \mathrm{ng} / \mathrm{ml}$ for
\end{tabular}


3). The estimates of 28-day cumulative incidence of therapeutic failure (Table 2) for these species were lower $(95 \%$ and $84 \%$ ) due to withdrawals caused by intercurrent parasitemia by the other species, prompting therapy. By either method of estimating risk for both species, chloroquine therapy routinely failed within 28 days. Comparing these estimates of risk with earlier studies in the same region, ${ }^{5-9}$ suggests an apparently rapid deterioration of therapeutic efficacy for P. vivax.

An attractive option for bringing combined therapies to bear on the problem of drug-resistant malaria is chloroquine plus pyrimethamine/sulfadoxine. The interest in this regimen, with good efficacy demonstrated in a few studies and interventions, ${ }^{15,16}$ stems largely from the relative ease with which it could be adopted. Both drugs are already stocked by government-operated clinics across Indonesia. Health care providers need only change how they administer the drugs, thereby substantially saving on administrative/education costs compared with introducing new therapies. A critical question for this strategy is efficacy against a backdrop of resistance to chloroquine and pyrimethamine/sulfadoxine as monotherapies. When is it too late to apply the combined therapy with a reasonable expectation of good efficacy? Finding that threshold becomes a vital public health issue where deployment of combined chloroquine and sulfadoxine/pyrimethamine may be considered. Areas having risk of therapeutic failure exceeding that threshold may be targeted for more effective (and expensive) therapies. Reliable estimates of resistance to chloroquine and sulfadoxine/pyrimethamine should guide information-based decisions on adopting either a new first line combined therapy, or deploying relatively expensive alternatives. In the specific case of northeastern Papua, the available data ${ }^{6,8,10}$ support abandoning chloroquine therapy either as monotherapy or combined with another agent. This heavily malarious region seems a good candidate for targeted distribution of artemisinin derivatives combined with mefloquine or another agent that has not yet lost clinical efficacy.

Standard protocols for therapeutic assessments of drugs for the treatment of uncomplicated malaria strive to accomplish uniformity across laboratories and investigators representing a wide range of capabilities. The tests present realistic goals with respect to obtaining useful information in the setting of a rural health clinic in the tropics. A national program successfully developing such a surveillance network will possess a powerful tool for information-based decisions on malaria therapy policies and practice. Indonesia has not yet developed such a network. The relatively few studies of the therapeutic response to standard antimalarials come from research laboratories. Research laboratories may have compelling reasons to not follow standardized protocols for surveillance of resistance. These facilities typically send a team of specialists to a remote area with the intent of obtaining as much useful information as possible within a practical time. For example, teams of specialists living in Jakarta cannot remain indefinitely at a remote health clinic in far off Papua. Personal and economic priorities necessarily minimize time spent in the field. Therefore, it is not often possible to follow standardized protocols designed and intended for rural health clinic staff resident at the site. The passive collection of study subjects is not practical for the visiting research team. Instead, research teams actively seek out study subjects by mass slide screening, essentially as described in this study. Also, we have found it impractical to exclude patients with parasitemias less than $1,000 / \mu \mathrm{L}$ for $P$. falciparum or less than $300 / \mu \mathrm{L}$ for $P$. vivax. In the areas we work, $85 \%$ of otherwise eligible subjects fall below these levels. Strict adherence to this criterion would result in a diminishingly small sample size within the time constraints imposed by a visiting research team. Moreover, systematic exclusion of relatively low-grade parasitemia, often representing the majority of patients presenting for treatment, could create a deeply biased sample with respect to estimating risk of therapeutic failure in a community. We also include patients with mixed infections of $P$. falciparum and $P$. vivax. Our microscopists consistently and reliably detect mixed infections and are not confused by the species identity of the recurrence. The intent of broader inclusion criteria is maximizing the collection of useful information obtained from the remote post with a fixed and relatively brief period, while also minimizing risk of sample bias in the estimate of risk.

In summary, we documented nearly complete resistance to chloroquine by $P$. falciparum and $P$. vivax in non-immune Javanese migrants taking residence in hyperendemic to holoendemic northeastern Papua, Indonesia. We know of no other area of Indonesia with such high risk of therapeutic failure with chloroquine. These findings support adopting a therapeutic strategy tailored to this region, and provide a backdrop of risk of therapeutic failure for evaluations of combined therapies that include chloroquine as treatment options.

Received August 14, 2002. Accepted for publication December 23, 2002.

Acknowledgments: We thank the officials of the Ministry of Health, Government of Indonesia, especially Dr. Sumaryati Aryoso in Jakarta; Dr. Slamet Harjosuwarno and Dr. Lana of the Provincial Health Service in Jayapura, Papua; Patriot, Mantri Hendrik, and Sukimin; Sofyan Sauri (the Department of Transmigration officer in charge of Arso Pir V) and his assistant, Supriyanto, for their advice and assistance.

Financial support: This work was supported by the U.S. Department of Defense Global Emerging Infections Surveillance Program.

Disclaimer: The views of the authors expressed herein are their own and do not purport to reflect those of the U.S. Navy or the Department of Defense.

Authors' addresses: Iwa W. Sumawinata, Budhi Leksana, Awalludin Sutamihardja, Purnomo, and J. Kevin Baird, U.S. Naval Medical Research Unit No. 2, American Embassy, Jakarta, Indonesia, FPO AP 96520-8132, Fax: 62-21-424-4507, E-mail: bairdjk@namru2.med. navy.mil. Bernadeta and Budi Subianto, Provincial Health Service, Abepura, Papua, Indonesia. Sekartuti, Infectious Disease Research Center, Ministry of Health, Jakarta, Indonesia. David J. Fryauff, Malaria Program, Naval Medical Research Center, 503 Robert Grant Avenue, Silver Spring, MD 20910-7500.

\section{REFERENCES}

1. World Health Organization, 2000. Criteria for Antimalarial Drug Selection Policy. Informal Consultation on the Use of Antimalarial Drugs, November 13-17, 2000. Geneva: World Health Organization. Background Paper 17.

2. Wellems TE, Plowe CV, 2001. Chloroquine-resistant malaria. J Infect Dis 184: 770-776.

3. Kitua AY, 1999. Antimalarial drug policy: making a systematic change. Lancet 354 (Suppl 4): 32. 
4. Fevre EM, Barnish G, 1999. Malaria treatment policies: when and how should they be changed? Ann Trop Med Parasitol 93: 549-560.

5. Baird JK, Basri H. Purnomo, Bangs MJ, Patchen L, Hoffman SL, 1991. Resistance to chloroquine by Plasmodium vivax in Irian Jaya, Indonesia. Am J Trop Med Hyg 44: 547-552.

6. Baird JK, Basri H, Jones TR, Bangs MJ, Ritonga A, 1991. Resistance to antimalarials in northeastern Irian Jaya, Indonesia. Am J Trop Med Hyg 44: 640-644.

7. Baird JK, Basri H, Subianto B, Fryauff DJ, McElroy PD, Leksana B, Richie TL. Masbar S, Wignall FS, Hoffman SL, 1995. Treatment of chloroquine resistant Plasmodium vivax with chloroquine and primaquine or halofantrine. J Infect Dis 171: $1678-1682$.

8. Baird JK, Wiady I, Fryauff DJ, Sutanihardja MA, Leksana B, Widjaya H, Kysdarmanto, Subianto B, 1997. In vivo resistance to chloroquine by Plasmodium vivax and Plasmodium falciparum at Nabire, Irian Jaya, Indonesia. Am J Trop Med Hyg 56: 627-631.

9. Murphy GS, Basri H, Purnomo, Andersen EM, Bangs MJ, Mount DL, Gorden J, Lal AA, Purwokusumo AR, Harjosuwarno S, Sorensen K, Hoffman SL, 1993. Vivax malaria resistant to treatment and prophylaxis with chloroquine. Lancet 341: 96-100.

10. Taylor WR, Widjaja H, Richie TL, Basri H, Ohrt C, Tjitra, Taufik E, Jones TR, Kain KC, Hoffman SL, 2001. Chloroquine/ doxycycline combination versus chloroquine alone, and doxycycline alone for the treatment of Plasmodium falciparum and
Plasmodium vivax malaria in northeastern Irian Jaya. Am J Trop Med Hyg 64: 223-228.

11. Taaken W, Knols BGJ, 1990. A taxonomic and bionomic review of the malaria vectors of Indonesia. Wageningen Agric Univ Papers 90: 9-62.

12. Baird JK, Purnomo, Basri H, Bangs MJ, Andersen EM, Jones TR, Masbar S, Harjosuwarno S, Subianto B, Arbani PR, 1993. Age-specific prevalence of Plasmodium falciparum among six populations with limited histories of exposure to endemic malaria. Am J Trop Med Hyg 49: 707-719.

13. Patchen LC, Mount DL, Schwartz IK, Churchill FC, 1983. Analysis of filter paper-absorbed, finger-stick blood samples for chloroquine and its major metabolite using high performance liquid chromatography with fluorescence detection. J Chromatogr 278: 932-935.

14. Baird JK, Leksana B, Masbar S, Fryauff DJ, Sutanihardja MA, Suradi, Wignall FS, Hoffman SL, 1997. Diagnosis of resistance to chloroquine by Plasmodium vivax: timing of recurrence and whole blood chloroquine levels. Am J Trop Med Hyg 56: 621626.

15. McIntosh HM, Greenwood BM, 1998. Chloroquine or amodiaquine combined with sulfadoxine-pyrimethamine as a treatment for uncomplicated malaria: a systematic review. Ann Trop Med Parasitol 92: 265-270.

16. Kaneko A, Taleo G, Kalkoa G, Yamar S, Kobayakawa T, Bjorkman A, 2000. Malaria eradication on islands. Lancet 356: 15601564. 